\title{
Menstrual Disturbances in Premenopausal Women with End-Stage Renal Disease: A Cross-Sectional Study
}

\author{
Chong-Ting Lin ${ }^{a}$ Xi-Ning Liu ${ }^{a}$ Hong-Lei Xu ${ }^{a}$ Hui-Yan Sui ${ }^{b}$ \\ a Department of Hemodialysis Room, Yantaishan Hospital, and ${ }^{\mathrm{b}}$ Department of Radiology, Yantai Hospital of \\ Traditional Chinese Medicine, Yantai, China
}

\section{Key Words}

Dialysis · End-stage renal disease - Menstrual disturbances .

Premenopausal status · Renal replacement therapy · Sex hormones

\begin{abstract}
Objective: To evaluate menstrual disturbances and sex hormonal status in premenopausal women with end-stage renal disease (ESRD). Subjects and Methods: The study consisted of 184 patients with ESRD treated with one of four treatment modalities (46/modality): conventional hemodialysis (CHD), continuous ambulatory peritoneal dialysis (CAPD), nocturnal hemodialysis (NHD) and renal transplantation (RT). Blood samples were collected to determine sex hormone levels. Sociodemographic and clinical data were collected from medical records. A questionnaire was administered to analyze menstrual patterns, and the final analysis included 46, 43, 40 and 36 patients in the CHD, CAPD, NHD and RT groups, respectively. Results: The overall prevalence of menstrual disturbances was $64.2 \%$ for all four treatment modalities (RT: 50\%; NHD: 55\%; CAPD: $72.1 \%$, and CHD: $76.1 \%)$. Serum prolactin levels were significantly lower $(p<$ $0.01)$ in the NHD $(25.1 \pm 10.9 \mathrm{ng} / \mathrm{ml})$ and RT $(13.4 \pm 5.1 \mathrm{ng} /$ $\mathrm{ml}$ ) groups than in the CHD group $(55.2 \pm 10.8 \mathrm{ng} / \mathrm{ml})$. Serum progesterone levels were significantly higher $(p<0.01)$ in
\end{abstract}

the NHD $(25.7 \pm 8.3 \mathrm{nmol} / \mathrm{l})$ and $\mathrm{RT}(30.1 \pm 5.9 \mathrm{nmol} / \mathrm{l})$ groups than in the CHD group $(17.7 \pm 7.3 \mathrm{nmol} / \mathrm{l})$. Moreover, the hormonal status (follicle-stimulating hormone, luteinizing hormone and testosterone) was much closer to normal in the NHD and RT groups compared to the other two groups. Conclusions: In this study, successful transplantation and NHD partially improved the symptoms of menstrual disturbances. Therefore, we recommend that further studies are necessary to confirm our finding in ESRD patients.

๑) 2016 S. Karger AG, Basel

\section{Introduction}

The correlation of end-stage renal disease (ESRD) with infertility has been highlighted in recent years [1], as ovulation in an altered hormonal milieu can cause infertility [2]. Menstruation is associated with ovulation, and one of the cardinal signs of anovulation is the irregularity or absence of a menstrual period [3]. Thus, there is a close correlation between infertility and menstrual disturbances in premenopausal women. Menstrual disturbances, especially secondary amenorrhea, are commonly seen among premenopausal women with ESRD [4]. It is postulated that elevated serum prolactin (PRL) levels may partly contribute to the occurrence of menstrual disturbances

\begin{tabular}{ll}
\hline KARGER & $\begin{array}{l}\text { ○ 2016 S. Karger AG, Basel } \\
1011-7571 / 16 / 0253-0260 \$ 39.50 / 0 \quad \text { Karger }\end{array}$ \\
E-Mail karger@karger.com & $\begin{array}{l}\text { Thisis an Open Access article licensed under the terms of the } \\
\text { Creative Commons Attribution-NonCommercial 3.0 Un- } \\
\text { ported license (CC BY-NC) (www.karger.com/OA-license), } \\
\text { applicable to the online version of the article only. Distribu- } \\
\text { tion permitted for non-commercial purposes only. }\end{array}$
\end{tabular}

Hui-Yan Sui

Department of Radiology, Yantai Hospital of Traditional Chinese Medicine No. 39 Xingfu Road, Zhifu District, Yantai 264000 (PR China)

E-Mail hongyanli2014@163.com 
[5]. The mechanisms for hyperprolactinemia in chronic renal failure are not well defined, but a possible cause could be an increased autonomous production rate of PRL; however, in ESRD patients, a decreased metabolic clearance rate might also play a role [6].

Factors other than sex hormone imbalances could also be responsible for menstrual disturbances since ovarian function is intact in ESRD patients, but other hormones, such as leptin, are abnormal $[7,8]$. In general, the serum leptin level is significantly elevated in patients with kidney failure compared with controls matched for age and body mass index [9]. Leptin appears to be one factor influencing the maturation of the gonadotropin-releasing hormone pulse generator.

Some hormonal disturbances can be corrected by normalization of the serum PRL level through improving renal replacement therapy such as nocturnal hemodialysis (NHD) or renal transplantation (RT) $[10,11]$. Despite successful RT, in previous studies $[12,13]$, menstrual disturbances were commonly seen in premenopausal women with ESRD. Thus, the role and effects of RT on menstrual cycle remodeling in premenopausal women with ESRD remain controversial. Hence, in this cross-sectional study, we aimed to evaluate the prevalence of menstrual disturbances and sex hormonal status in premenopausal women receiving different types of renal replacement therapy at our hospital.

\section{Patients and Methods}

Ethical permission was obtained from the Scientific Committee at the Yantaishan Hospital and the Yantai Hospital of Traditional Chinese Medicine. Written informed consent was obtained from all the patients before enrollment. Exclusion criteria were genital tract infection, clotting disturbances, a history of menstrual disturbances before chronic kidney disease and use of sex hormones in the prior 2 years. A total of 184 patients were initially enrolled and divided equally into four groups (each $n=46$ ) based on the type of renal replacement therapy: conventional hemodialysis (CHD), continuous ambulatory peritoneal dialysis (CAPD), NHD and RT. Patients were 14-44 years old and had received more than 6 months of renal replacement therapy. In the RT group, the transplanted organs were obtained from executed prisoners $(n=34)$ or cadaveric donors $(n=12)$.

Nineteen patients did not complete the final analysis because of the following reasons: not providing the characteristics of the menstrual cycle (6 patients), switching to another renal replacement therapy (8 patients) or missing information about the serum hormonal status ( 5 patients). The 19 excluded patients were from the following groups: CAPD, 3; NHD, 6, and RT, 10. Hence, 165 of the initial 184 patients completed the study. Menstrual patterns in the 165 patients were recorded in detail. Menstrual cycles were classified into polymenorrhea ( $<22$ days), normal (22-35 days)

Menstrual Disturbances in Uremic Women and oligomenorrhea ( $>35$ days). Absence of menses for at least 6 months was diagnosed as secondary amenorrhea.

From menstruating women, blood samples were collected once during the 1st month after admission after overnight fasting for the measurement of serum sex hormonal status, including PRL, follicle-stimulating hormone (FSH), luteinizing hormone (LH), progesterone and testosterone. Blood samples were prepared by storing blood at $4^{\circ} \mathrm{C}$ for $1 \mathrm{~h}$, and the resulting coagulated blood cells were then separated from the serum by centrifugation at $4,000 \mathrm{~g}$ for $20 \mathrm{~min}$. The serum samples were transferred to new microtubes and stored at $-80^{\circ} \mathrm{C}$ until analysis. Blood samples for the detection of PRL, FSH and LH were collected in the morning on days 3-5 of the cycle, and the hormones were measured using chemiluminescence. Blood samples for the detection of progesterone and testosterone were collected 4-6 days before anticipated menses and hormone levels were also measured using chemiluminescence. In nonmenstruating women, the levels of serum sex hormones were measured once on the same day.

\section{Prescription of Dialysis and $R T$}

The dialysis prescriptions were as follows: the CHD group: $4 \mathrm{~h} /$ session and 3 sessions/week; the CAPD group: 3 exchanges/day; the NHD group: 6-8 h/session and $4-5$ sessions/week. The RT group underwent a full functioning RT (serum creatinine $0.8-1.3$ $\mathrm{mg} / \mathrm{dl}$ and glomerular filtration rate $>90 \mathrm{ml} / \mathrm{min}$ ), and all patients were on a stable corticosteroid immunosuppressive regimen for at least 6 months.

\section{Demographic and Clinical Data at Baseline}

Demographic data including menstrual patterns, the duration of primary kidney disease as well as the type, number and duration of medications for kidney disease were collected by questionnaire completed by the patients. Age, body mass index, primary kidney disease leading to renal failure, renal replacement modality, duration of renal replacement (months) and laboratory data including hemoglobin and residual kidney function (assessment of urinary volume) were obtained from medical records. All patients were given immunosuppressive therapy if necessary according to their previous condition. The use of corticosteroids and immunosuppressive drugs is summarized in table 1. A questionnaire was administered for the menstrual pattern.

\section{Statistical Analysis}

All values are expressed as means \pm SD or percentages as appropriate. A two-tailed $\mathrm{p}<0.05$ was considered significant. Differences in proportions were tested using Pearson's $\chi^{2}$ test; differences in means were tested using one-way analysis of variance or the MannWhitney test as appropriate. All statistical analyses were evaluated using SPSS 18.00 (IBM Corporation, Armonk, N.Y., USA).

\section{Results}

\section{Patients' Characteristics}

The demographic and socioeconomic characteristics of the total population are summarized in table 1 . The mean age of the patients was $34.7 \pm 5.3$ years. There were no significant differences in sociodemographic and clinical data among the four groups. 
Table 1. Sociodemographic and clinical data of the patients

\begin{tabular}{|c|c|c|c|c|c|}
\hline & $\begin{array}{l}\text { CHD group } \\
(n=46)\end{array}$ & $\begin{array}{l}\text { CAPD group } \\
(\mathrm{n}=43)\end{array}$ & $\begin{array}{l}\text { NHD group } \\
(\mathrm{n}=40)\end{array}$ & $\begin{array}{l}\text { RT group } \\
(\mathrm{n}=36)\end{array}$ & $\begin{array}{l}\mathrm{p} \\
\text { value }\end{array}$ \\
\hline Age, years & $34.6 \pm 5.4$ & $34.5 \pm 5.8$ & $35.2 \pm 5.1$ & $34.5 \pm 4.8$ & 0.21 \\
\hline Primary kidney disease, $\%$ & & & & & 1.0 \\
\hline Glomerulonephritis & 58.7 & 60.5 & 62.5 & 61.1 & \\
\hline Pyelonephritis & 4.3 & 4.6 & 5.0 & 5.6 & \\
\hline Hypertensive nephrosclerosis & 8.7 & 9.3 & 10.0 & 8.3 & \\
\hline Polycystic kidney disease & 8.7 & 4.6 & 2.5 & 5.5 & \\
\hline Lupus nephritis & 4.3 & 4.6 & 7.5 & 2.8 & \\
\hline Other & 0 & 2.4 & 0 & 2.8 & \\
\hline Duration of renal disease, years & $4.7 \pm 1.3$ & $4.5 \pm 1.5$ & $4.8 \pm 2.2$ & $4.7 \pm 1.6$ & 0.17 \\
\hline Body mass index & $23.5 \pm 7.5$ & $23.7 \pm 6.3$ & $24.1 \pm 4.9$ & $23.8 \pm 5.2$ & 0.63 \\
\hline Hemoglobin, g/l & $11.7 \pm 2.8$ & $12.1 \pm 8.9$ & $12.5 \pm 4.5$ & $11.6 \pm 2.4$ & 0.11 \\
\hline Tripterygium glycosides & 17.4 & 16.3 & 17.5 & 19.4 & 0.99 \\
\hline Number of medications for kidney disease ${ }^{1}, \%$ & & & & & 0.98 \\
\hline$<2$ medications & 28.3 & 27.9 & 25.0 & 25.0 & \\
\hline$\geq 2$ medications & 71.7 & 72.1 & 75.0 & 75.0 & \\
\hline Duration of medication use for kidney disease ${ }^{1}, \%$ & & & & & 0.99 \\
\hline$<2$ years & 6.5 & 7.0 & 7.5 & 8.3 & \\
\hline$\geq 2$ years & 93.5 & 93.0 & 92.5 & 91.7 & \\
\hline Dialysis duration, months & $52.2 \pm 7.8$ & $48.5 \pm 11.3$ & $51.9 \pm 10.1$ & $49.8 \pm 10.2$ & 0.49 \\
\hline Dialysis sessions, n/week & $3.2 \pm 0.3$ & & $5.5 \pm 0.5$ & & 0.03 \\
\hline Duration of dialysis sessions, $\mathrm{h}$ & $4.3 \pm 0.2$ & & $7.4 \pm 1.6$ & & 0.02 \\
\hline Total dialysis time, $\mathrm{h} /$ week & $11.1 \pm 1.9$ & & $35.3 \pm 4.7$ & & 0.003 \\
\hline Weight after dialysis, kg & $67.7 \pm 8.3$ & $66.9 \pm 10.1$ & $65.6 \pm 5.2$ & & 0.42 \\
\hline
\end{tabular}

${ }^{1}$ Medications associated with ovarian function include glucocorticoids, immunosuppressants and tripterygium glycosides.

Table 2. Prevalence rates of various menstrual disturbances according to the different types of renal replacement therapy

\begin{tabular}{lllll}
\hline & $\begin{array}{l}\text { CHD group } \\
(\mathrm{n}=35)\end{array}$ & $\begin{array}{l}\text { CAPD group } \\
(\mathrm{n}=31)\end{array}$ & $\begin{array}{l}\text { NHD group } \\
(\mathrm{n}=22)\end{array}$ & $\begin{array}{l}\text { RT group } \\
(\mathrm{n}=18)\end{array}$ \\
\hline Amenorrhea & $60 \%$ & $58.1 \%$ & $54.5 \%$ & $61.1 \%$ \\
Polymenorrhea & $22.9 \%$ & $25.8 \%$ & $27.3 \%$ & $38.9 \%$ \\
Oligomenorrhea & $17.1 \%$ & $16.1 \%$ & $18.2 \%$ & $0 \%$ \\
\hline
\end{tabular}

\section{Prevalence of Menstrual Disturbances in the Different} Groups

The overall prevalence of menstrual disturbances was $64.2 \%$, and for each treatment modality, it was 76.1, 72.1, 55.00 and $50.0 \%$ for the CHD, CAPD, NHD and RT groups, respectively. The prevalence of menstrual disturbances was highest in the CHD group and lowest in the RT group $(\mathrm{p}<0.05)$. The top two menstrual disturbances were secondary amenorrhea and polymenorrhea (table 2), which accounted for more than $85 \%$ of all menstrual disturbances in the four groups. Oligomenorrhea was the least frequent disturbance among the four groups. 
Table 3. Hormonal status in menstruating and nonmenstruating patients among the different groups

\begin{tabular}{|c|c|c|c|c|}
\hline Characteristics & CHD group & CAPD group & NHD group & RT group \\
\hline Menstruating patients, $\mathrm{n}$ & 11 & 12 & 18 & 18 \\
\hline Serum PRL, ng/ml & $55.2 \pm 10.8$ & $46.4 \pm 8.3$ & $25.1 \pm 10.9^{* *}$ & $13.4 \pm 5.1^{* *}$ \\
\hline Serum FSH, $\mu \mathrm{IU} / \mathrm{ml}$ & $21.2 \pm 10.4$ & $18.4 \pm 6.6$ & $18.2 \pm 7.3$ & $17.7 \pm 6.3$ \\
\hline Serum $\mathrm{LH}, \mu \mathrm{IU} / \mathrm{ml}$ & $31.1 \pm 17.4$ & $26.5 \pm 10.5$ & $26.9 \pm 10.1$ & $25.2 \pm 7.3$ \\
\hline Serum progesterone, $\mathrm{nmol} / \mathrm{l}$ & $17.7 \pm 7.3$ & $18.4 \pm 6.6$ & $25.7 \pm 8.3^{* *}$ & $30.1 \pm 5.9^{* *}$ \\
\hline Serum testosterone, $\mathrm{ng} / \mathrm{ml}$ & $0.48 \pm 0.25$ & $0.49 \pm 0.13$ & $0.44 \pm 0.16$ & $0.53 \pm 0.21$ \\
\hline Nonmenstruating patients, $\mathrm{n}$ & 35 & 31 & 22 & 18 \\
\hline Serum PRL, ng/ml & $218.4 \pm 39.1$ & $185.6 \pm 38.4$ & $135.2 \pm 45.8^{* *}$ & $93.6 \pm 11.4^{* *}$ \\
\hline Serum FSH, $\mu \mathrm{IU} / \mathrm{ml}$ & $135.8 \pm 56.4$ & $122.3 \pm 31.8$ & $107.6 \pm 14.4^{*}$ & $75.9 \pm 22.1^{* *}$ \\
\hline Serum $\mathrm{LH}, \mu \mathrm{IU} / \mathrm{ml}$ & $65.8 \pm 29.2$ & $68.1 \pm 22.9$ & $48.1 \pm 13.9^{*}$ & $36.3 \pm 23.7^{* *}$ \\
\hline Serum progesterone, $\mathrm{nmol} / \mathrm{l}$ & $9.1 \pm 4.4$ & $9.5 \pm 5.2$ & $9.7 \pm 4.3$ & $10.2 \pm 6.8$ \\
\hline Serum testosterone, $\mathrm{ng} / \mathrm{ml}$ & $0.37 \pm 0.23$ & $0.39 \pm 0.15$ & $0.56 \pm 0.17^{*}$ & $0.71 \pm 0.29 * *$ \\
\hline
\end{tabular}

\section{Hormonal Status in the Different Groups}

The hormonal status of menstruating and nonmenstruating patients in the four groups is shown in table 3. Serum PRL levels were significantly lower in the NHD $(\mathrm{p}<0.01)$ and RT $(\mathrm{p}<0.01)$ groups compared to the CHD group for both menstruating and nonmenstruating patients $(\mathrm{p}<0.05)$. Among the menstruating patients, there was no significant difference in serum FSH, LH or testosterone levels between the four groups ( $p>0.05)$. However, serum progesterone levels were significantly higher in the NHD ( $\mathrm{p}<0.01)$ and RT $(\mathrm{p}<0.01)$ groups than in the CHD group. Moreover, sex hormonal status (including FSH, $\mathrm{LH}$ and testosterone) was close to normal in the NHD and RT groups, although the mean remained slightly above or below the normal range. No difference was evident in the serum progesterone levels in the nonmenstruating patients among the four groups ( $p>0.05)$.

\section{Discussion}

The overall prevalence of menstrual disturbances in premenopausal women with ESRD was $64.2 \%$, which was lower than the $75.0 \%$ reported in previous studies $[14,15]$ which investigated only CHD. The difference could be attributed to the fact that we included NHD and RT separately besides $\mathrm{CHD}$, which had prevalences of 55.0 and $50.0 \%$, respectively, and, hence, both were more effective than CHD in lowering the prevalence of menstrual disturbances because the corresponding prevalence of $\mathrm{CHD}$ was $76.1 \%$. In this study, the prevalence rates of menstrual disturbances of $76.1 \%$ (CHD) and $72.1 \%$ (CAPD) did not support the theory that CAPD outperforms CHD in preserving residual renal function and promoting PRL excretion as previously stated [16], and thus could benefit the menstrual cycles in premenopausal patients with ESRD. A possible explanation could be that CAPD is not very effective in the above two areas (preserving residual renal function and promoting PRL excretion) [17].

Menstrual disturbances were still common even after successful RT (50\%), which was in agreement with a previous study [18]. It has been postulated that the hypothalamic-pituitary-gonadal axis is permanently altered following ESRD, although the normalization of hormonal status could be influenced by immunosuppressive treatments and other medications, such as corticosteroids and $\beta$-blockers [19]. As previously reported, the use of immunosuppressants (e.g. cyclophosphamide) or tripterygium contributes to premature ovarian failure [20, 21]. Moreover, systemic lupus erythematosus, a common cause of ESRD, can influence the menstrual pattern [22]. Depressive disorder was seen among ESRD patients [23], and depression can have a negative effect on the menstrual cycle [24]. A majority of ESRD patients suffer from one or more chronic illnesses, such as hypertension, anemia and diabetes mellitus. Moreover, chronic disorders, especially diabetes mellitus, can cause menstrual disturbances through alterations in the hypothalamic-pituitary-gonadal axis [25]. All of these factors might contribute to the menstrual disturbances in premenopausal women with 
ESRD. However, we did not study these potentially relevant factors influencing menstrual disturbances.

In our study, more than half of the menstrual disturbances were due to secondary amenorrhea, which is within the $24-63 \%$ reported in previous reviews [26, 27]. Hyperprolactinemia might also contribute to this discrepancy. Serum PRL levels were significantly more normal in the NHD and RT groups than in the other two groups regarding both menstruating and nonmenstruating patients $(\mathrm{p}<0.05)$ in our study. One reason for this might be that NHD could result in a decreased peak and flattened curve of secreted PRL $[28,29]$. Also, the total dialysis time per week was significantly longer in the NHD group than in the CHD group $(35.3 \pm 4.7$ vs. $11.1 \pm 1.9 \mathrm{~h} /$ week, respectively), which improved serum PRL removal. RT was more advantageous than the other three therapies because (1) RT restores residual renal function, since the kidney can remove $25 \%$ of serum PRL from the circulation [30], and (2) it restores menses and fertility, as indicated by the normalization of the hormonal serum profile [18]. Meanwhile, a circadian rhythm difference in serum
PRL levels is known to be involved in the differences across studies. We also observed a more significant improvement in the status of other hormones with an elevation of the circulating progesterone level in the NHD $(\mathrm{p}<0.01)$ and RT $(\mathrm{p}<0.01)$ groups compared with the CHD group among menstruating patients based on decreased levels of uremic toxins or restoration of residual renal function.

\section{Conclusion}

In this study, successful transplantation or NHD improved the symptoms of menstrual disturbances. However, further studies are necessary to confirm our findings in ESRD patients.

\section{Disclosure Statement}

The authors have no conflict of interest.

\section{References}

1 Holley JL, Schmidt RJ: Changes in fertility and hormone replacement therapy in kidney disease. Adv Chronic Kidney Dis 2013;20: 240-245.

2 Johansen KL: Testosterone metabolism and replacement therapy in patients with endstage renal disease. Semin Dial 2004;17:202208.

3 Rathi M, Ramachandran R: Sexual and gonadal dysfunction in chronic kidney disease: pathophysiology. Indian J Endocrinol Metab 2012;16:214-219.

4 Fryckstedt J, Hylander B: Sexual function in patients with end-stage renal disease. Scand J Urol Nephrol 2008;42:466-471.

5 Dal Maso RC, Cavagna NM, Yu L, et al: Sex hormones profile in women on dialysis program in treatment with erythropoietin (in Portuguese). Rev Assoc Med Bras 2003;49: 418-423.

-6 Antonucci M, Palermo G, Recupero SM, et al: Male sexual dysfunction in patients with chronic end-stage renal insufficiency and in renal transplant recipients. Arch Ital Urol Androl 2016;87:299-305.

7 Brannian JD, Hansen KA: Leptin and ovarian folliculogenesis: implications for ovulation induction and ART outcomes. Semin Reprod Med 2002;20:103-112.

8 Chou SH, Mantzoros C: 20 years of leptin: role of leptin in human reproductive disorders. J Endocrinol 2014;223:T49-T62. $\checkmark$ Kayardi M, Icagasioglu S, Yilmaz A, et al: Serum leptin levels and malnutrition in patients with chronic renal failure. Saudi Med J 2006; 27:477-481.

10 Filocamo MT, Zanazzi M, Li MV, et al: Sexual dysfunction in women during dialysis and after renal transplantation. J Sex Med 2009;6: 3125-3131.

11 Barua M, Hladunewich M, Keunen J, et al: Successful pregnancies on nocturnal home hemodialysis. Clin J Am Soc Nephrol 2008;3: 392-396.

12 Kim JM, Song RK, Kim MJ, et al: Hormonal differences between female kidney transplant recipients and healthy women with the same gynecologic conditions. Transplant Proc 2012;44:740-743.

13 Ghazizadeh S, Lessan-Pezeshki M, Mahdavi $\mathrm{M}$, et al: Menstrual problems among kidney transplant recipients. Transplant Proc 2003; 35:2720-2721.

14 Matuszkiewicz-Rowinska J, Skorzewska K, Radowicki S, et al: Endometrial morphology and pituitary-gonadal axis dysfunction in women of reproductive age undergoing chronic haemodialysis - a multicentre study. Nephrol Dial Transplant 2004;19:2074-2077.

15 Shanmugavadivoo K, Shaariah W: Health issues in dialysis-dependent female patients. Perit Dial Int 2003;23(suppl 2):S192-S195.
16 Sinnakirouchenan R, Holley JL: Peritoneal dialysis versus hemodialysis: risks, benefits, and access issues. Adv Chronic Kidney Dis 2011; 18:428-432.

17 Kagan A, Gertler A, Ulman M, et al: Serum levels and peritoneal loss of prolactin in CAPD patients. Adv Perit Dial 1991;7:247252.

18 Tauchmanova L, Carrano R, Sabbatini M, et al: Hypothalamic-pituitary-gonadal axis function after successful kidney transplantation in men and women. Hum Reprod 2004; 19:867-873.

19 Peng YS, Chiang CK, Kao TW, et al: Sexual dysfunction in female hemodialysis patients: a multicenter study. Kidney Int 2005;68:760765.

20 Deng J, Huo D, Wu Q, et al: A meta-analysis of randomized controlled trials comparing tacrolimus with intravenous cyclophosphamide in the induction treatment for lupus nephritis. Tohoku J Exp Med 2012;227:281-288.

21 Zhu B, Wang Y, Jardine M, et al: Tripterygium preparations for the treatment of CKD: a systematic review and meta-analysis. Am J Kidney Dis 2013;62:515-530.

22 Tseng JC, Lu LY, Hu JC, et al: The impact of systemic lupus erythematosus on women's sexual functioning. J Sex Med 2011;8:33893397. 
23 Chen SF, Wang IJ, Lang HC: Risk of major depression in patients with chronic renal failure on different treatment modalities: a matched-cohort and population-based study in Taiwan. Hemodial Int 2016;20:98-105.

24 Harlow BL, Wise LA, Otto MW, et al: Depression and its influence on reproductive endocrine and menstrual cycle markers associated with perimenopause: the Harvard Study of Moods and Cycles. Arch Gen Psychiatry 2003;60:29-36.

25 Arrais RF, Dib SA: The hypothalamus-pituitary-ovary axis and type 1 diabetes mellitus: a mini review. Hum Reprod 2006;21:327-337.
26 Matuszkiewicz-Rowinska J, Skorzewska K, Radowicki S, et al: The benefits of hormone replacement therapy in pre-menopausal women with oestrogen deficiency on haemodialysis. Nephrol Dial Transplant 1999;14: 1238-1243.

27 Holley JL, Schmidt RJ, Bender FH, et al: Gynecologic and reproductive issues in women on dialysis. Am J Kidney Dis 1997;29:685690.
28 Niemczyk S, Matuszkiewicz-Rowinska J, Szamotulska K, et al: Circadian profile of the prolactin concentration in the patients with endstage renal failure (in Polish). Pol Arch Med Wewn 2006;116:1137-1143.

29 van Eps C, Hawley C, Jeffries J, et al: Changes in serum prolactin, sex hormones and thyroid function with alternate nightly nocturnal home haemodialysis. Nephrology (Carlton) 2012;17:42-47.

30 Yavuz D, Topcu G, Ozener C, et al: Macroprolactin does not contribute to elevated levels of prolactin in patients on renal replacement therapy. Clin Endocrinol (Oxf) 2005;63: 520-524. 